\title{
Factors that Contribute on Golden Hour Patient Stroke (Review on The Family)
}

\author{
Bernadetta Germia Aridamayanti ${ }^{1}$, Abdurahman Wahid ${ }^{2}$, Ifa Hafifah ${ }^{2}$, Helna Fitriana ${ }^{2}$ \\ $\underline{\text { dettagerman@gmail.com }}^{1^{*}}$, ns.wahid@unlam.ac.id ${ }^{2}, \underline{\text { ns.ifahafifah@gmail.com }}^{2}, \underline{\text { herlnafh@gmail.com }}^{2}$ \} \\ ${ }^{1}$ Faculty of Nursing, Universitas Airlangga, Kampus C Mulyorejo, Surabaya, East Java, 60115 \\ ${ }^{2}$ School of Nursing, Faculty of Medicine, Universitas Lambung Mangkurat, Jl. A. Yani KM. 36 \\ Banjarbaru, 70714 \\ *dettagerman@gmail.com
}

\begin{abstract}
Total of $62.8 \%$ of stroke patients come to the hospital with family> 4.5 hours due to several factors. This study was to determine the factors that play a role in the golden hour such as knowledge, education, perception and transportation. The ethical feasibility test is conducted at the Ethics Commission of the Faculty of Medicine, Lambung Mangkurat University. Using descriptive analytic method with cross sectional study with accidental sampling at 40 families of stroke patients. Analizing data using spearman test found knowledge ( $\mathrm{p}$ value $=0.001$ ), perception ( $\mathrm{p}$ value $=0.001$ ). Kruskal-Wallis education ( $p$ value $=0.913$ ), Mann-Whitney transportation $(p$ value $=0.474)$. Perception is a dominant factor in golden hour $(74.7 \%)$. Respondents have sufficient knowledge for the early detection so as to achieve the golden hour. However, the belief (perception) that patients experience emergency and assume that the symptoms will go away by itself so do not need to be taken to the hospital caused a delay.
\end{abstract}

Keywords: golden hour, stroke, patients, family, perception

\section{Introduction}

Stroke is one of the emergencies with treatment time $<4.5$ hours associated with fibrinolytic administration called golden hour. Fibrinolytics with rTPA (recombinant tissue plasminogen activator) in the first 3-4.5 hours after stroke onset generally provide reperfusion benefits from thrombus lysis and significant cerebral repair [1]. Handlers in the golden hour of stroke patients are very important because time is the brain. If this treatment is done slowly it will increase the motality and mordibity of stroke patients. The Banjarmasin stroke study form stated that as many as 35 stroke patients, $62.8 \%$ of them were delivered beyond 4.5 hours after the attack with an average arrival time of 8.9 hours and very far from golden hour [2]. Of these 35 patients, 33 of them occurred at home so that the largest initiator in decision making was family. The late arrival of these patients is influenced by several factors such as knowledge, education, perception and transportation contained in the initiator [3]. In accordance with the family's function in health, every family member must have adequate knowledge about symptoms and strokes as an emergency [4]. Initiators with tertiary education also accelerate decision making to deliver stroke patients [5]. One example of a wrong perception about a stroke is that a stroke occurs when you're angry and is caused by fatigue [6]. The ambulance unit that is equipped with specially trained officers also increases the time of arrival and the proportion of patients to the hospital so that they can get fibrinolytic therapy $[7,8]$.

The results of a preliminary study conducted by researchers on 25 families of stroke patients 4 of whom had the last elementary school education and 6 junior high schools which 
stated that golden hour was no more than 24 hours (a day), 9 high schools and 6 had attended college. Among 9 respondents from high school graduates, 4 said the same thing and the rest said they did not know the golden hour from a stroke. In addition, 55\% of $100 \%$ of patient arrivals use private cars that are supposed to use ambulances. When validating the questioner, interviews were conducted on 29 families of stroke patients and 17 of them said delaying the arrival of the patient because they perceive the stroke as physical fatigue due to strenuous activities carried out by the patient before.

\section{Methods}

Design uses descriptive analytic research method with cross sectional approach. This research was conducted at the General Hospital in Banjarmasin. Ethics test has been obtained from the Faculty of Medicine, Universitas Lambung Mangkurat. The sampling technique in this study is nonprobability sampling with accidental sampling design on 40 respondents who are stroke families. The questionnaire used in this study was adapted from the American Heart Association manual then evaluated by 2 experts in the field of stroke. Before the instrument was used, validity and reliability tests were carried out on 30 respondents at Banjarbaru Hospital and Martapura Hospital with calculated R values> R Table (0.361) and reliability values $\alpha>0.70$ which showed that the questionnaire was valid and could be used for assess perceptions and knowledge, while for transportation and education use observation sheets. In this case the researcher looks for factors that play a dominant role in golden hour including knowledge, education, perception and transportation.

\section{Results}

Based on research conducted at hospital in Banjarmasin, from 40 respondents obtained characteristics based on age and gender of stroke families.

\begin{tabular}{|c|c|c|}
\hline Variables & $\mathrm{N}$ & $\%$ \\
\hline \multicolumn{3}{|l|}{ Age } \\
\hline $17-25$ years & 6 & 15.0 \\
\hline $26-35$ years & 11 & 27.5 \\
\hline $36-45$ years & 14 & 35.0 \\
\hline $46-55$ years & 5 & 12.5 \\
\hline $56-65$ years & 4 & 10.0 \\
\hline Total & 40 & 100 \\
\hline \multicolumn{3}{|l|}{ Sex } \\
\hline Male & 23 & 57.5 \\
\hline Female & 17 & 42.5 \\
\hline Total & 40 & 100 \\
\hline
\end{tabular}

Based on the table 1 respondents with the most age are 36-45 years, amounting to 14 people with a percentage of $35.0 \%$, male gender totaling 23 people with a percentage of $57.5 \%$. 
Table 2. Correration of family knowledge of the golden hour

\begin{tabular}{lll}
\hline Variables & $\mathrm{p}$ Value & $\mathrm{R}$ \\
\hline Knowledge & 0.0001 & -0.586 \\
\hline Golden hour & & \\
\hline
\end{tabular}

Based on table 2 shows the results of the analysis of the correration of family knowledge with the golden hour of stroke patients using the Spearman correlation test, obtained a significance value (2-tailed) of $0.001<0.05$, so there is a relationship of family knowledge with the golden hour of stroke patients at Hospital in Banjarmasin with a value of $r$ $=-0.586(0.40-0.599)$ which means it has moderate strength in a negative direction, thus the higher the family's knowledge, the lower the golden hour value (the higher the knowledge the faster the time of arrival to the hospital).

Table 3. Correration of family education of the golden hour

\begin{tabular}{llll}
\hline Variables & \multicolumn{2}{l}{} & \multirow{2}{*}{$\mathrm{p}$ Values } \\
\cline { 2 - 3 } Education & \multicolumn{2}{l}{ Golden Hour } & \\
\cline { 2 - 3 } & $<4.5$ hours & $>4.5$ hours & \\
\hline Low & 7 & 4 & \\
\hline Moderate & 11 & 9 & \\
\hline High & 8 & 11 & \\
\hline Total & 26 & 14 & \\
\hline
\end{tabular}

Based on table 3 it can be seen that families with low education bring stroke patients $<4.5$ hours as many as 7 respondents and $>4.5$ hours as many as 4 respondents, families with education are carrying stroke patients $<4.5$ hours as many as 11 respondents and $>4.5$ hours as many as 9 respondents, families with higher education bring stroke patients $<4.5$ hours as many as 8 respondents and $>4.5$ hours as many as 11 respondents. The results of the analysis of the relationship of family education with the golden hour of stroke patients using the Kruskal-Wallis correlation test, obtained a significance value (2-tailed) of $0.913<0.05$.

Table 4. Correration of family perception of the golden hour

\begin{tabular}{lll}
\hline Variables & $\mathrm{p}$ Value & $\mathrm{R}$ \\
\hline Perception & 0.0001 & -0.858 \\
\hline Golden hour & & \\
\hline
\end{tabular}

Based on table 4 the results of the analysis of the correration of family perception with the golden hour of stroke patients using the Spearman correlation test, obtained a significance value (2-tailed) of $0.001<0.05$, so there is a relationship of family perception with the golden hour of stroke patients at Ulin Hospital Banjarmasin with a value of $r=-0.868$ which has a very strong force with a negative direction, thus the higher the value of family perception, the lower the value of golden hour (the better the perception the faster time of arrival to the hospital). 
Table 5. Relation of family transportation of the golden hour

\begin{tabular}{lll}
\hline Variables & $\mathrm{N}$ & $\%$ \\
\hline Transportations & & \\
Private (cars) & 32 & 80.0 \\
Ambulance & 8 & 20.0 \\
\hline Total & 40 & 100 \\
\hline
\end{tabular}

Based on table 5 it can be seen that the family of patients who bring stroke patients $<4.5$ hours as many as 19 people and $>4.5$ hours as many as 13 people and who use ambulance $<4.5$ hours as many as 7 people and $>4.5$ are 1 person. The results of the analysis of the relationship of family transportation with the golden hour of stroke patients using the MannWhitney correlation test, obtained a significance value (2-tailed) of $0.474<0.05$, so there is no significant relationship between transportation and golden hour.

Analysis of dominant factors among knowledge, education, perception and family transportation in the golden hour of stroke patients at Hospital in Banjarmasin using multivariate analysis. Multivariate Analysis used in this research is multiple linear regression. The selection of candidates uses simple linear regression by looking at the $p$ value $<0.25$ in the bivariate analysis as in the following table.

Table 6. Multivariate Variable Candidates

\begin{tabular}{lll}
\hline Variables & P Values & Candidates \\
\hline Knowledge & 0.000 & Included \\
\hline Education & 0.913 & Not included \\
\hline Perception & 0.000 & Included \\
\hline Transportation & 0.474 & Not included \\
\hline
\end{tabular}

Table 6 explains the variables with $\mathrm{p}$ value $<0.25$ that fulfill the multivariate test are knowledge and perception. While education and transportation variables $>0.25$, according to the theory cannot be included in multivariate analysis.

Table 7. Table Model Percentage Factors

\begin{tabular}{llllll}
\hline \multirow{2}{*}{ Model } & \multirow{2}{*}{ Variables } & \multicolumn{2}{l}{ Correlation Value } & $\%$ & ANOVA \\
\cline { 3 - 6 } & & Between Factors & Golden Hour & & p Value \\
\cline { 3 - 6 }$(1)$ & Perception \& Knowledge & 0,865 & 0,748 & 74,8 & 0,000 \\
\hline$(2)$ & Perception & 0,864 & 0,747 & 74,7 & 0,000 \\
\hline & Knowledge & - & 0,001 & 0,1 & - \\
\hline
\end{tabular}

Table 7 model (1) explains the magnitude of the correlation value or the relationship between knowledge and perception of golden hour of 0.865 . The effect of independent variables (knowledge and perception) on variables bound (golden hour) 0.748 with a percentage of $74.8 \%$. In model (2) explain the magnitude of the correlation value or the relationship between perception of golden hour of 0.864 . Effect of independent variables (perception) of the dependent variable (golden hour) is 0.747 with a percentage of $74.7 \%$. These results indicate that greater family perceptions affect the arrival (golden hour) of stroke patients to Ulin Hospital Banjarmasin with a percentage of $74.7 \%$, family knowledge is only $0.1 \%(74.7 \%-74.8 \%)$ and the remaining $25,2 \%$ is influenced by other variables not examined in this study. 


\section{Discussion}

In this study, the number of male respondents was 23 people with a percentage of $57.5 \%$. This explains that the position and role of men according to context and culture in Indonesia, men are the head of the family (number one), as the main and determinant in decision making and have strong control over material and assets compared to women [2,9]. Golden hour is a term used to indicate the effective time of stroke treatment in fibrinolytic administration, which is 3 to 4.5 hours (180-270 minutes), determined from the initial signs and symptoms of a stroke occurring until the patient arrives at the hospital in a prehospital chain of survival $[10,11]$. The number of respondents who took stroke patients to the hospital with a time of less than 270 minutes which means included in the golden hour is 26 people and the number of respondents who took stroke patients to the hospital with a time exceeding 270 minutes which means not included in the golden hour is 14 people.

Delayed help in the prehospital phase must be avoided by the introduction of complaints and symptoms of stroke for patients and those closest to them and the speed of bringing stroke patients to the hospital for immediate treatment [12,13]. Stroke patients should be treated with fibrinolytic administration with rTPA (recombinant tissue plasminogen activator) in the first 3-4.5 hours after stroke onset generally provides reperfusion benefits from thrombus lysis and significant cerebral repair $[14,15]$. This study is in line with previous research that explains knowledge related to family actions in the early treatment of acute stroke. However, this study is not in line with other studies which describe that knowledge does not have a significant relationship with the arrival of stroke patients to the hospital in the golden hour. Family knowledge about stroke is related to the golden hour of stroke patients because knowledge can influence a person in making decisions to take appropriate actions on stroke patients $[16,17]$.

Other variables, educations are declared not to have a significant relationship to the golden hour of stroke patients because it is caused by several factors such as culture, educational information competencies obtained and different curricula in each region, as well as research that draws on formal education without asking about non-formal education $[18,19]$. Education is an inseparable part of knowledge, which is expected if someone has a higher education, then that person has extensive knowledge [20]. However, that does not mean someone with low education has the same low knowledge. A person's knowledge can be increased without going through formal education, but it can be through non-formal education which can influence the respondent's knowledge [21]. Educational variables in this study are not related because they can be counfounding variables that affect other variables, namely knowledge. Characteristics of respondents based on different ages indicate that there are differences in years of education, in other words the curriculum in each school is also different and go to school outside of formal education.

Perception also influences the speed of stroke patients coming to the hospital. Society believes that if a stroke has occurred, there is no medical treatment that can help the patient [22]. The same study explains the influential perception of the delay in stroke patients contacting EMS assistance [2,23]. In addition, people often assume that numbness is a very common sign of fatigue without the need for treatment $[15,24]$. In this study the ambulance facility affects the family speed of carrying stroke patients in the early treatment of acute stroke $[25,26]$. However, other research states there is no relationship between transportation with the speed of stroke patients to the hospital [27]. This can be influenced by distance, type of ambulance and its facilities as well as health workers who play a role during the trip in order to get thrombolysis therapy as soon as possible [8]. 


\section{Conclusions}

The conclusion of this study is that there are several roles of the factors in stroke patients' golden hour. Of the 4 factors namely knowledge, education, perception and transportation, only 2 factors play a role namely knowledge $(\mathrm{p}$ value $=0.001)$ and perception ( $\mathrm{p}$ value $=0.001)$. Knowledge affects the family in the golden hour of stroke patients to the hospital that is $0.1 \%$. Perception is the dominant and biggest factor affecting the family in the golden hour of stroke patients to the hospital that is equal to $74.7 \%$. Meanwhile, education (p value $=0.913)$ and transportation $(\mathrm{p}$ value $=0.474)$. The results showed there were $25.5 \%$ of other factors that affected the golden hour of stroke patients. This can be a recommendation for future researchers to conduct research by examining these factors such as social and economic.

\section{References}

[1] Braddock Clarke SE. The golden hour. Selvedge. 2016;11(70):22-4.

[2] Ebinger M, Kunz A, Wendt M, Rozanski M, Winter B, Waldschmidt C, et al. Effects of golden hour thrombolysis: A Prehospital Acute Neurological Treatment and Optimization of Medical Care in Stroke (PHANTOM-S) substudy. JAMA Neurol. 2015;72(1):25-30.

[3] Tsai P, Yip P-K, Tai JJ, Lou M-F. Needs of family caregivers of stroke patients : a longitudinal study of caregivers ' perspectives. Patient Prefer Adherence. 2015;9:44957.

[4] Winstein CJ, Stein J, Arena R, Bates B, Cherney LR, Cramer SC, et al. Guidelines for Adult Stroke Rehabilitation and Recovery: A Guideline for Healthcare Professionals from the American Heart Association/American Stroke Association. Vol. 47, Stroke. 2016. 98-169 p.

[5] Varjoranta T, Raatiniemi L, Majamaa K, Martikainen M, Liisanantti JH. Prehospital and hospital delays for stroke patients treated with thrombolysis: A retrospective study from mixed rural-urban area in Northern Finland. Australas Emerg Care [Internet]. 2019;22(2):76-80. Available from: https://doi.org/10.1016/j.auec.2019.01.008

[6] Sciberras A, Scerri J. Facilitators and barriers to treatment with haemodialysis among persons in mid-adulthood: an interpretative phenomenological analysis. Scand J Caring Sci. 2017;31(4):695-701.

[7] Bowry R, Grotta JC. Bringing Emergency Neurology to Ambulances: Mobile Stroke Unit. Semin Respir Crit Care Med. 2017;38(6):713-7.

[8] Petzäll K, Petzäll J, Jansson J, Nordström G. Time saved with high speed driving of ambulances. Accid Anal Prev. 2011;43(3):818-22.

[9] Lissete González Oquendo., José Miguel Morales Asencio., Candela Bonill de las Nieves. Contributing Factors for Therapeutic Diet Adherence in Patients Receiving Haemodialysis Treatment: An integrative review. Int J Lab Hematol. 2016;38(1):42-9.

[10] Gonz J. Factors Associated with Shortening of Prehospital Delay among Patients with Acute Ischemic Stroke. 2019;

[11] Faiz KW, Sundseth A, Thommessen B, Rønning OM. Factors Related to Decision Delay in Acute Stroke. J Stroke Cerebrovasc Dis [Internet]. 2014;23(3):534-9. Available from: http://dx.doi.org/10.1016/j.jstrokecerebrovasdis.2013.05.007

[12] Franck JA, Smeets RJEM, Seelen HAM. Evaluation of a functional hand orthosis combined with electrical stimulation adjunct to arm-hand rehabilitation in subacute 
stroke patients with a severely to moderately affected hand function. Disabil Rehabil [Internet]. 2019;41(10):1160-8. Available from: https://doi.org/10.1080/09638288.2017.1423400

[13] Golden AP, Odoi A. Emergency medical services transport delays for suspected stroke and myocardial infarction patients. BMC Emerg Med [Internet]. 2015;15(1):1-13. Available from: http://dx.doi.org/10.1186/s12873-015-0060-3

[14] Sadeghi-Hokmabadi E, Farhoudi M, Taheraghdam A, Rikhtegar R, Ghafouri RR, Asadi R, et al. Prehospital notification can effectively reduce in-hospital delay for thrombolysis in acute stroke. Future Neurol. 2018;13(1):5-11.

[15] Bahnasy WS, Ragab OAA, Elhassanien ME. Stroke onset to needle delay: Where these golden hours are lost? An Egyptian center experience. eNeurologicalSci. 2019;14(December 2018):68-71.

[16] Liu X, Weng Y, Liu R, Zhao J. Significant Stroke Knowledge Deficiencies in Community Physician Improved with Stroke 120. J Stroke Cerebrovasc Dis. 2019;1-6.

[17] Johansen ML, O’Brien JL. Decision Making in Nursing Practice: A Concept Analysis. Nurs Forum. 2016;51(1):40-8.

[18] Ashraf V V., Maneesh M, Praveenkumar R, Saifudheen K, Girija AS. Factors delaying hospital arrival of patients with acute stroke. Ann Indian Acad Neurol. 2015;18(2):162-6.

[19] Rahmina Y, Wahid A, Agustina R. Tingkat Pendidikan Keluarga Terhadap Golden Hour Pasien Stroke Di Rsud Ulin Banjarmasin. Dunia Keperawatan. 2017;5(1):68.

[20] Gonzalez-Aquines A, Cordero-Pérez AC, Cristobal-Niño M, Pérez-Vázquez G, Góngora-Rivera F. Contribution of Onset-to-Alarm Time to Prehospital Delay in Patients with Ischemic Stroke. J Stroke Cerebrovasc Dis. 2019;28(11):1-6.

[21] Nepal G, Yadav JK, Basnet B, Shrestha TM, Kharel G, Ojha R. Status of prehospital delay and intravenous thrombolysis in the management of acute ischemic stroke in Nepal. BMC Neurol. 2019;19(1):1-9.

[22] Kaddumukasa M, Kayima J, Kaddumukasa MN, Ddumba E, Mugenyi L, Pundik S, et al. Knowledge, attitudes and perceptions of stroke : a cross _ sectional survey in rural and urban Uganda. BMC Res Notes. 2015;8:1-7.

[23] Sobral S, Taveira I, Seixas R, Vicente AC, Duarte J, Goes AT, et al. Late Hospital Arrival for Thrombolysis after Stroke in Southern Portugal: Who Is at Risk? J Stroke Cerebrovasc Dis. 2019;28(4):900-5.

[24] Fladt J, Meier N, Thilemann S, Polymeris A, Traenka C, Seiffge DJ, et al. Reasons for Prehospital Delay in Acute Ischemic Stroke. J Am Heart Assoc. 2019;8(20):e013101.

[25] Andsberg G, Esbjörnsson M, Olofsson A, Lindgren A, Norrving B, von Euler M. PreHospital Ambulance Stroke Test - pilot study of a novel stroke test. Scand J Trauma Resusc Emerg Med. 2017;25(1):1-6.

[26] Madhok DY, Keenan KJ, Cole SB, Martin C, Hemphill JC. Prehospital and Emergency Department-Focused Mission Protocol Improves Thrombolysis Metrics for Suspected Acute Stroke Patients. J Stroke Cerebrovasc Dis. 2019;1-6.

[27] Harth A, Jüttler E, Kulla M. Golden hour of stroke - Der Schlaganfall im Rettungsdienst. Notarzt. 2016;32(2):88-94. 